\title{
An Examination of Concussion Legislation in the United States
}

Kelly L. Potteiger

Northern Illinois University, kelpotteiger@gmail.com

Adam J. Potteiger

Ann and Robert H. Lurie Children's Hospital of Chicago, apotteiger@luriechildrens.org

William Pitney

wpitney@niu.edu

Paul M. Wright

Northern Illinois University, pwright@niu.edu

Follow this and additional works at: https://nsuworks.nova.edu/ijahsp

Part of the Medicine and Health Sciences Commons

\section{Recommended Citation}

Potteiger KL, Potteiger AJ, Pitney W, Wright PM. An Examination of Concussion Legislation in the United States. The Internet Journal of Allied Health Sciences and Practice. 2018 Jan 01;16(2), Article 6.

This Opinion Piece is brought to you for free and open access by the College of Health Care Sciences at NSUWorks. It has been accepted for inclusion in Internet Journal of Allied Health Sciences and Practice by an authorized editor of NSUWorks. For more information, please contact nsuworks@nova.edu. 


\title{
An Examination of Concussion Legislation in the United States
}

\begin{abstract}
There is legislation in the United States designed to protect children and adolescents from the risks associated with concussion. The scope and reach of these laws vary greatly.

Purpose: It is important that health care professionals are aware of the limitations of each law. Since 2009 , every state in the nation and the District of Columbia passed legislation designed to protect studentathletes who suffer from concussions resulting from participation in sport.

Method: Therefore, select components of state policies were identified including: 1) Affected entities, 2) Stipulations for concussion awareness/education, 3) Requirements for removal/return to play, and 4) Requirements for return to the classroom.

Results: There is significant variance between the laws and not all children/adolescents are protected equally.

Conclusion: Concussion policies are a minimum standard and, when available, best practices should be followed.
\end{abstract}

\section{Author Bio(s)}

Kelly L Potteiger, Ph.D., ATC is an Associate Professor and Atheltic Training Program Director at Northern Illinois University in DeKalb, IL.

Adam J. Potteiger, MS, ATC is a Senior Athletic Trainer at Ann \& Robert H. Lurie Children's Hospital of Chicago in Chicago, IL.

Wiliam A. Pitney, Ed.D., ATC, FNATA is the Associate Dean of Research, Resources, and Innovation for the College of Education at Northern Illinois University in DeKalb, IL.

Paul M. Wright, Ph.D. is a Professor at Northern Illinois University in DeKalb, IL. 


\title{
IJAHSP \\ The Internet Joưnal of Allied Health Sciences and Practice
}

Dedicated to allied health professional practice and education

Vol. 16 No. 2 ISSN 1540-580X

\section{An Examination of Concussion Legislation in the United States}

\author{
Kelly L. Potteiger, Ph.D., ATC1 \\ Adam J. Potteiger, MS, ATC2 \\ William A. Pitney, Ed.D., ATC, FNATA ${ }^{1}$ \\ Paul M. Wright, Ph.D ${ }^{1}$ \\ 1. Northern Illinois University \\ 2. Ann and Robert H. Lurie Children's Hospital of Chicago \\ United States
}

\begin{abstract}
There is legislation in the United States designed to protect children and adolescents from the risks associated with concussion. The scope and reach of these laws vary greatly. Purpose: It is important that health care professionals are aware of the limitations of each law. Since 2009, every state in the nation and the District of Columbia passed legislation designed to protect studentathletes who suffer from concussions resulting from participation in sport. Method: Therefore, select components of state policies were identified including: 1) Affected entities, 2) Stipulations for concussion awareness/education, 3) Requirements for removal/return to play, and 4) Requirements for return to the classroom. Results: There is significant variance between the laws and not all children/adolescents are protected equally. Conclusion: Concussion policies are a minimum standard and, when available, best practices should be followed.
\end{abstract}

\section{INTRODUCTION}

Each year, traumatic brain injuries are estimated to effect 1.7 million people in the United States. ${ }^{1}$ Between 70 to $90 \%$ of these injuries are mild and are commonly referred to as "concussions". ${ }^{2}$ Sport-related concussions in youth are common and may significantly impact on a person's life. ${ }^{3}$ One such person was 13 -year-old Zackery Lystedt who was severely debilitated after sustaining a head injury while playing football in 2006. ${ }^{4}$ Three years later, in May of 2009, the State of Washington passed the first legislation surrounding concussion in sport. Known as the Lystedt Law, this legislation was developed to provide consistent policy across schools in the state of Washington in an effort to prevent student-athletes from participating in sport while suffering from concussion symptoms. Over the next five years, every state and the District of Columbia enacted similar legislation. ${ }^{5}$ These laws are particularly important because concussions are more dangerous for children and adolescents whose brains are still developing and may be more susceptible to the effects of concussions. ${ }^{6}$ While these policies are a start in the effort to protect young athletes from the risks of concussion, the policies are varied in comprehensiveness.

Many healthcare professionals (e.g. MD, DO, PA) are well trained in the recognition, diagnosis, and management of concussions. However, athletic trainers are the only healthcare professionals whose primary practice setting is traditionally located within athletic departments and/or facilities. ${ }^{7}$ When present, these healthcare providers serve as the first line of defense against sport-related concussions. However, they are not present at every youth sporting event in the United States. ${ }^{8}$ Due to the variability between healthcare professionals who are charged to care for sport-related concussions, and given the variety among the purview of state laws, it is important all healthcare professionals are aware of the limitations of each state's legislation. Therefore, the purpose of this study was to provide a comprehensive review of current concussion legislation in the United States. Specifically, it is our aim to assist healthcare professionals to recognize the limitations of such policies and identify trends in policy revision.

\section{METHODS}

Because of the text-based nature of the data, the researchers used a qualitative content analysis. ${ }^{9}$ This qualitative approach uses a quantitatively oriented technique whereby standardized measures are used to metrically define units in order to characterize and 
compare documents. ${ }^{10}$ For this study, descriptive statistics were used to portray the current state of concussion legislation in the United States. Data was obtained directly from each state's official website (e.g. www.il.gov) through September, 2017. One member of the research team reviewed the policies, identified key metrics and preformed the initial coding. After all state laws were examined and coded, a peer debriefer reviewed the codes, reexamined state laws as needed and collapsed the categories into 4 distinct themes. Consistent interpretation and application of codes was assessed through peer debriefing meetings. Overall, a high level of consistency was found. In cases where there were disagreements, the coders deliberated until consensus was reached.

An audit trail, peer debriefing, and multi analyst triangulation were used to establish trustworthiness. The audit trail was established during initial data analysis to record how the textual content was coded and categorized. Then, the peer debriefer, examined audit trail, coding scheme, and frequency counts to further analyze the data and ensure coding was applied consistency to each piece of legislation. Peer debriefing was conducted by individuals with an understanding of the clinical application of the law. The peers examined the audit trail and legislation from each state to ensure each was appropriately coded.

\section{RESULTS}

The analysis revealed four themes among concussion legislation: 1) affected entities, 2) concussion awareness/education, 3) requirements for removal/return to play, and 4) requirements for return to the classroom. Descriptive statistics were used to determine the number of states requiring each criterion.

\section{Affected Entities}

All 50 states and the District of Columbia currently have legislation regarding sport-related concussions. Thirty-seven percent $(n=19)$ of the mandates apply only to students enrolled in public schools (Figure 1). Only $33 \%(n=17)$ policies are inclusive to public, private, and youth sports organizations. There are some exceptions to this rule. In the state of Maine, private schools enrolling more than $60 \%$ of students at the public's expense are included within the state's mandate. In some cases, the organizations overseeing the activity or the facility where the activity is held can a make a difference. For the states of Massachusetts and South Carolina, the policies apply only to public schools participating in each state's high school athletic association. The age of the individual can also determine eligibility for protection. Almost two-thirds of the policies $(n=32,63 \%)$ protect all student-athletes as defined by language such as "K-12", "ages 7 to 18", or "ages 18 and under". Sixteen percent $(n=8)$ of mandates include only high school students while the remaining $22 \%(n=11)$ protection is limited to high school and middle school students (Figure 2).

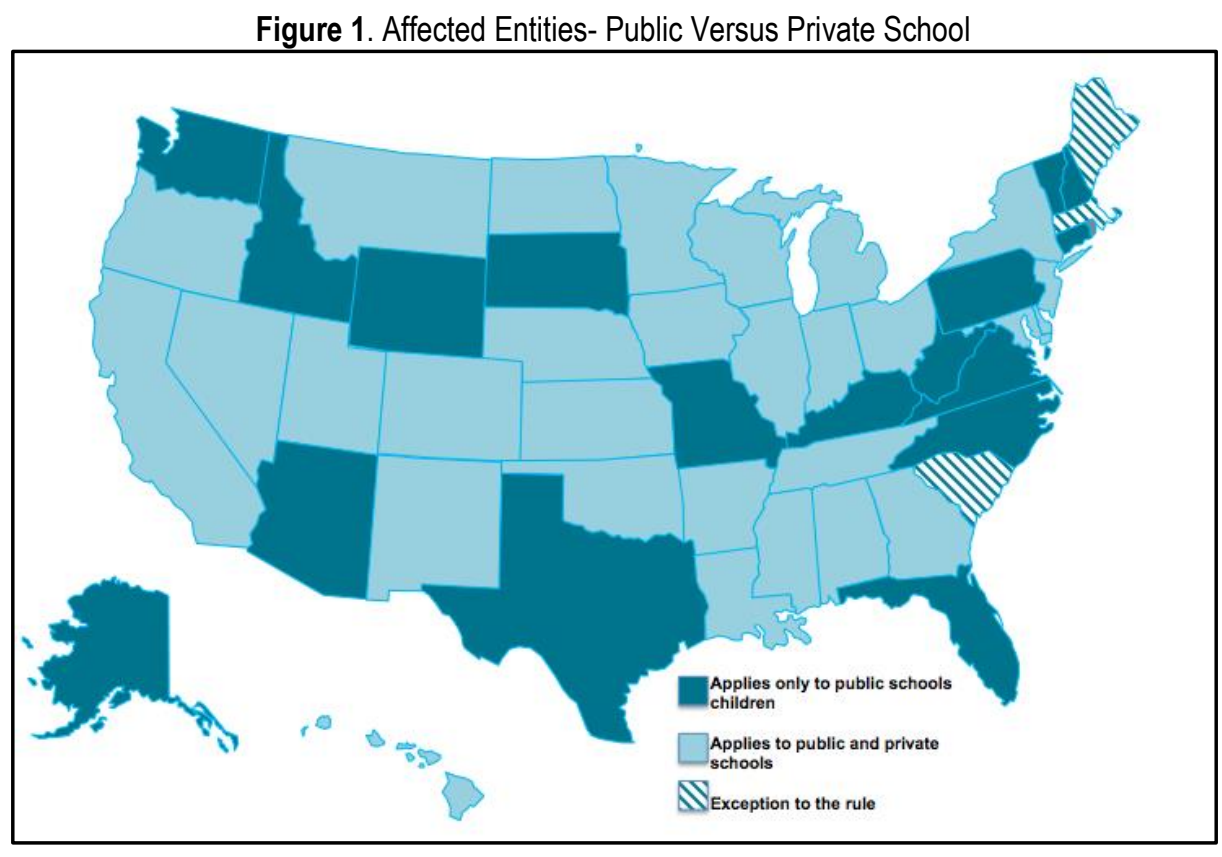

(C) The Internet Journal of Allied Health Sciences and Practice, 2018 
Figure 2. Affected Entity Stratified by Age

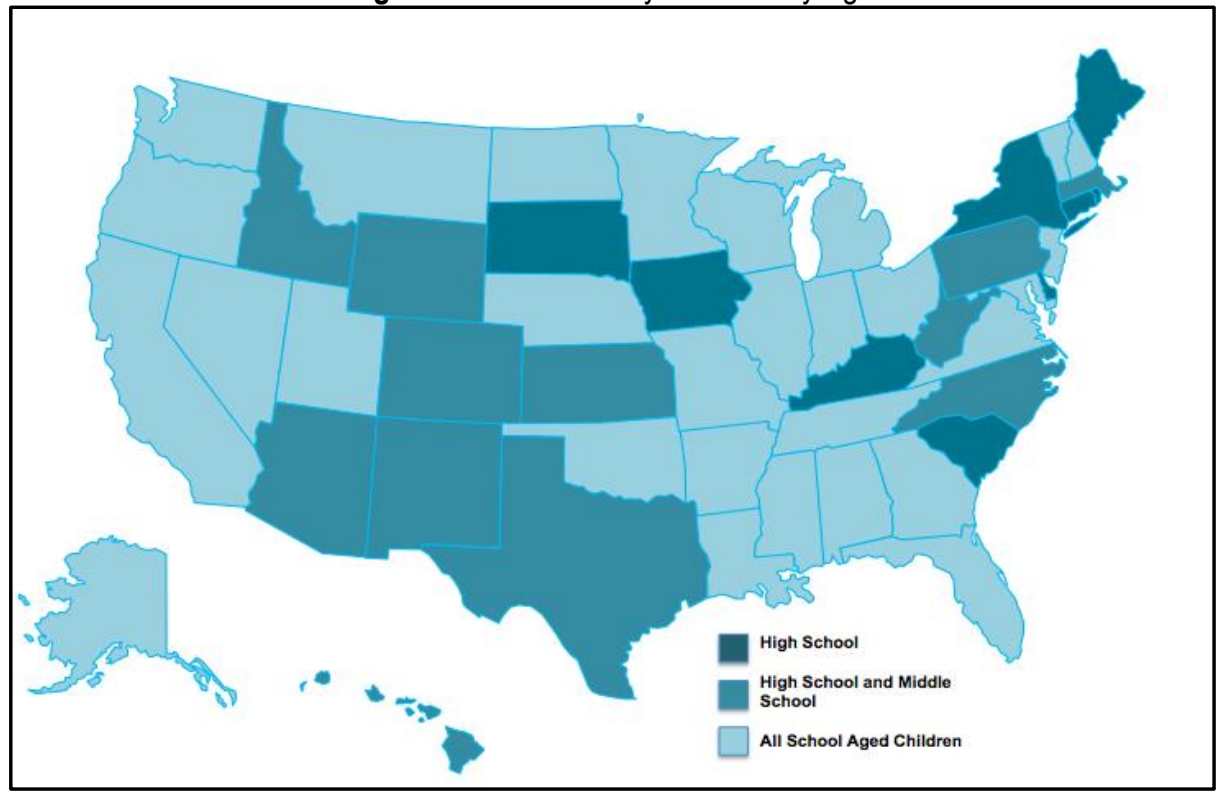

\section{Education/Awareness}

All $(n=51,100 \%)$ policies required some form of concussion education or awareness training. As part of this educational requirement, most $(n=48,94 \%)$ states require an informed consent document signed prior to participation in sports. Of the 43 policies requiring student-athlete education, $86 \%(n=36)$ policies suggest the education is in the form of informed consent only. Ninety percent $(n=46)$ of the laws also mandate concussion training for coaches. Approximately one-third $(n=15,31 \%)$ requires coaches to update their training annually, $19 \%(n=9)$ require biennial training, and $8 \%(n=4)$ require repeat training every $3-5$ years (Figure 3). Six percent $(n=3)$ of states require one-time training of coaches while another $33 \%(n=16)$ do not specify a timeframe for repeat training. Most states recommend some form of concussion education or awareness for other stakeholders as well (Figure 4). The most common recommendation is education for students/athletes (i.e. informed consent, $n=43,84 \%)$, parents ( $n=17,33 \%)$, healthcare providers (i.e. athletic trainers, school nurses; $n=12,24 \%)$, and game officials $(n=11,22 \%)$. Fifty-three percent $(n=27)$ of the policies do not specify the type of content included within the educational initiative and instead designate a specified entity (i.e. Department of Education, State Association, or Interscholastic League) to design the educational materials. One fourth of the policies $(n=13,25 \%)$ do not specify the type of content or who is responsible for providing the education. Only $12 \%(n=6)$ provide specific guidelines to the types of information provided in a concussion awareness program.

Figure 3. Educational Requirements for Coaches $(\mathrm{N}=46,90 \%)$

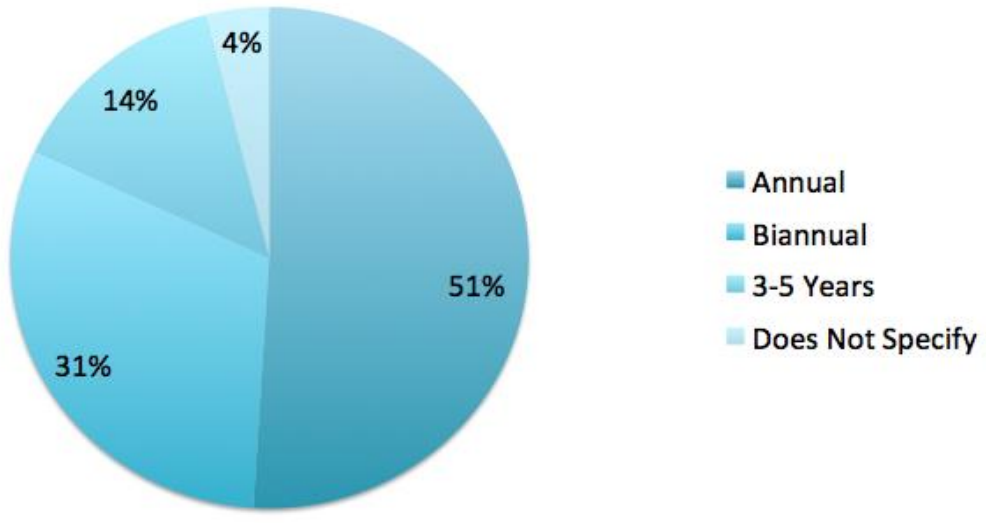


Figure 4. States With Educational Requirements for Other Stakeholders

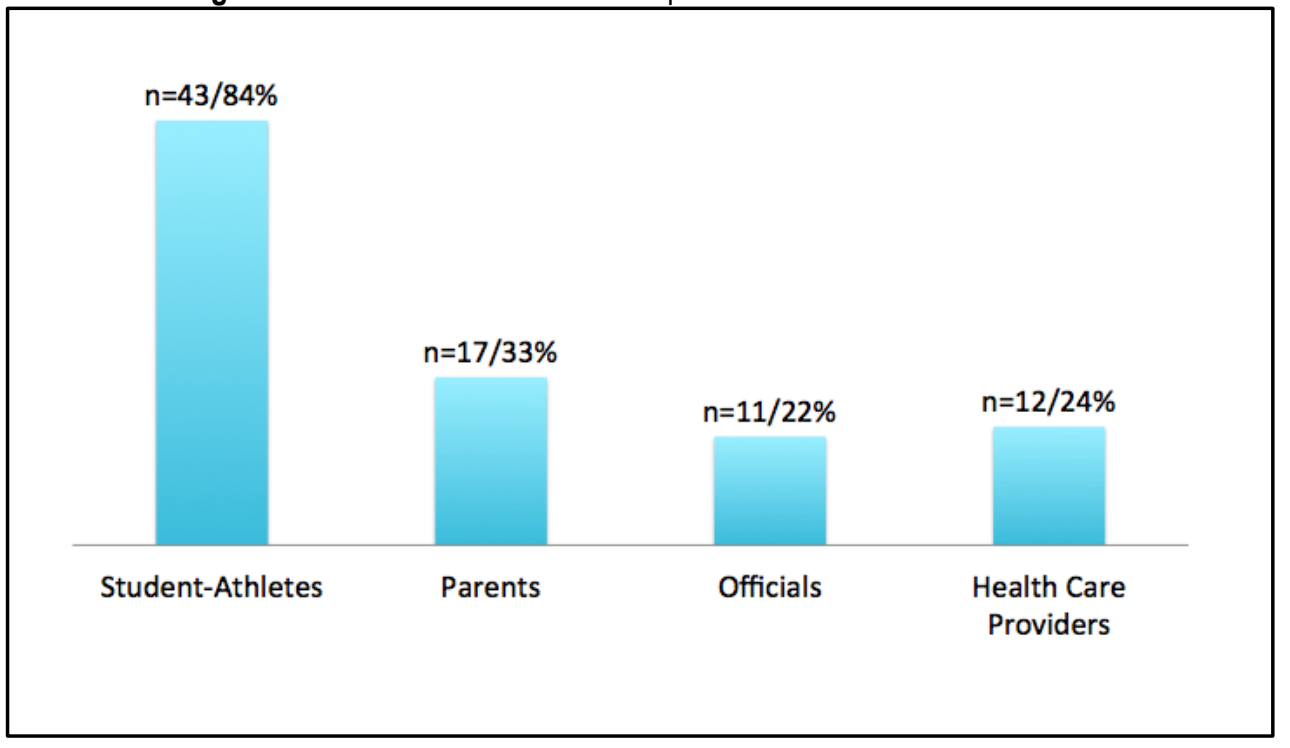

\section{Removal/Return to Play}

Education to alert stakeholders to the signs and symptoms of a concussion is important since all $50(100 \%)$ state policies mandate removal from play if a concussion is suspected. Once an athlete is removed from play, he/she cannot return to participation until a qualified healthcare professional evaluates the athlete and determines whether a concussion was sustained. In most states $(n=49$, $96 \%$ ), the injury and subsequent release cannot occur within 24 hours/on the same day as symptoms of concussion are often delayed. The only exceptions are Arizona and South Carolina's legislation. In these states, students participating in covered entity can return to play the same day if cleared by a designated healthcare professional. Conversely, the state of New Mexico recently extended the mandatory period of rest after an athlete suffers a concussion to 10 days or 240 hours after the injury occurred. ${ }^{11}$

The type of healthcare professional legally able to clear an athlete for return to participation also varies by state. Twenty-three states (45\%) allow for any healthcare professional to make the decision; although, some states stipulate the healthcare professional must be trained in the evaluation and management of concussions. In $39 \%(n=20)$ of the policies, only select health professionals can legally clear an athlete for participation. The most commonly cited healthcare professionals with authority to clear an athlete for participation are Allopathic Physicians (Medical Doctors [MD]), Osteopathy Physicians (DO), Physician's Assistants (PA), Nurse Practitioners (NP), Athletic Trainers (AT), Physical Therapist (PT), and Chiropractors (DC). Allopathic and Osteopathic Physicians are authorized to clear athletes for return to participation in 100\% $(n=50 / 50)$ of the states. Physician Assistant and Nurse Practitioners are authorized to clear athletes for return to participation in $(n=42 / 50)$ of the states. Athletic trainers are authorized to clear athletes for return to participation in $80 \%(\mathrm{~N}=40 / 50)$ of the states. Physical Therapists are authorized to clear athletes for return to participation in $52 \%(\mathrm{~N}=26 / 50)$ of the states. In addition to the 23 states that allow any healthcare professional to make the decision, the state of lowa includes Doctors of Chiropractic (DC) and Physical Therapists (PT) in their list of eligible healthcare providers. PTs are also eligible healthcare providers in Nevada and Pennsylvania. Sixteen percent of state policies $(n=8)$ only allow physicians (MDs or DOs) to return an athlete to participation . 
Table 1. Healthcare Professionals with Legal Authorization to Clear an Athlete for Participation after a Concussion

\begin{tabular}{|c|c|c|}
\hline $\begin{array}{l}\text { Any Licensed Healthcare Provider/ } \\
\text { Healthcare Providers Trained in } \\
\text { Concussion Management }\end{array}$ & $\begin{array}{c}\text { Limited to select Healthcare } \\
\text { Providers (e.g. MD, DO, PA, NP, AT) }\end{array}$ & Physician Only (MD or DO) \\
\hline Alaska & Arizona & Alabama \\
\hline Arkansas & Colorado* & Indiana \\
\hline California & Connecticut & Kansas \\
\hline District of Columbia & Delaware & Kentucky \\
\hline Florida & Georgia & New Jersey \\
\hline Hawaii & Idaho $^{\wedge}$ & New York \\
\hline Illinois & lowa & North Dakota \\
\hline Maine & Louisiana* & Rhode Island \\
\hline Maryland & Massachusetts & \\
\hline Michigan & Mississippi & \\
\hline Minnesota & Nebraska & \\
\hline Missouri & North Carolina & \\
\hline Montana & New Mexico & \\
\hline New Hampshire & Nevada & \\
\hline Ohio^ & Oregon & \\
\hline Oklahoma & Pennsylvania & \\
\hline South Dakota & South Carolina & \\
\hline Tennessee $^{\wedge}$ & Texas $^{\wedge}$ & \\
\hline Utah & Virginia & \\
\hline Vermont & Washington & \\
\hline \multicolumn{3}{|l|}{ West Virginia } \\
\hline \multicolumn{3}{|l|}{ Wisconsin } \\
\hline Wyoming & & \\
\hline
\end{tabular}

${ }^{*} \mathrm{ATs}$ are not included

${ }^{\wedge}$ Must be supervised by a physician

\section{Return to Learn}

Since 2011, 12 states (23\%) either passed new legislation or revised existing policy to include language concerning the academic implications of participating in a formal learning environment after suffering from a head injury (Figure 5). While not mandated, a thirteenth state, California, recommended schools utilize a return to learn protocol in the 2015 revision of their law. ${ }^{12}$ Two states' law (IL, TX, 4\%) require the creation of concussion oversight teams (COT) as part of their concussion policy. ${ }^{13,14}$ This interdisciplinary team is made up of officials from the healthcare and sports realms to develop return to participation policies for each school. In Illinois, the creation of the COT is the responsibility of each individual school and includes officials from the academic sector to help guide return to learn decisions. ${ }^{13}$ In Texas, the COT is established by each school district and its focus is only on the student's return to participation in sports. ${ }^{14}$ The state of Texas requires each COT to include at least one Texas licensed physician. ${ }^{14}$ When athletic trainers are employed by the district (Texas) or school (Illinois), the COT must also include an athletic trainer.13,14 Both states require all members of the COT to complete training in the evaluation, treatment and oversight of concussions. 
Figure 5. Return to the Classroom Policy (Return to Learn)

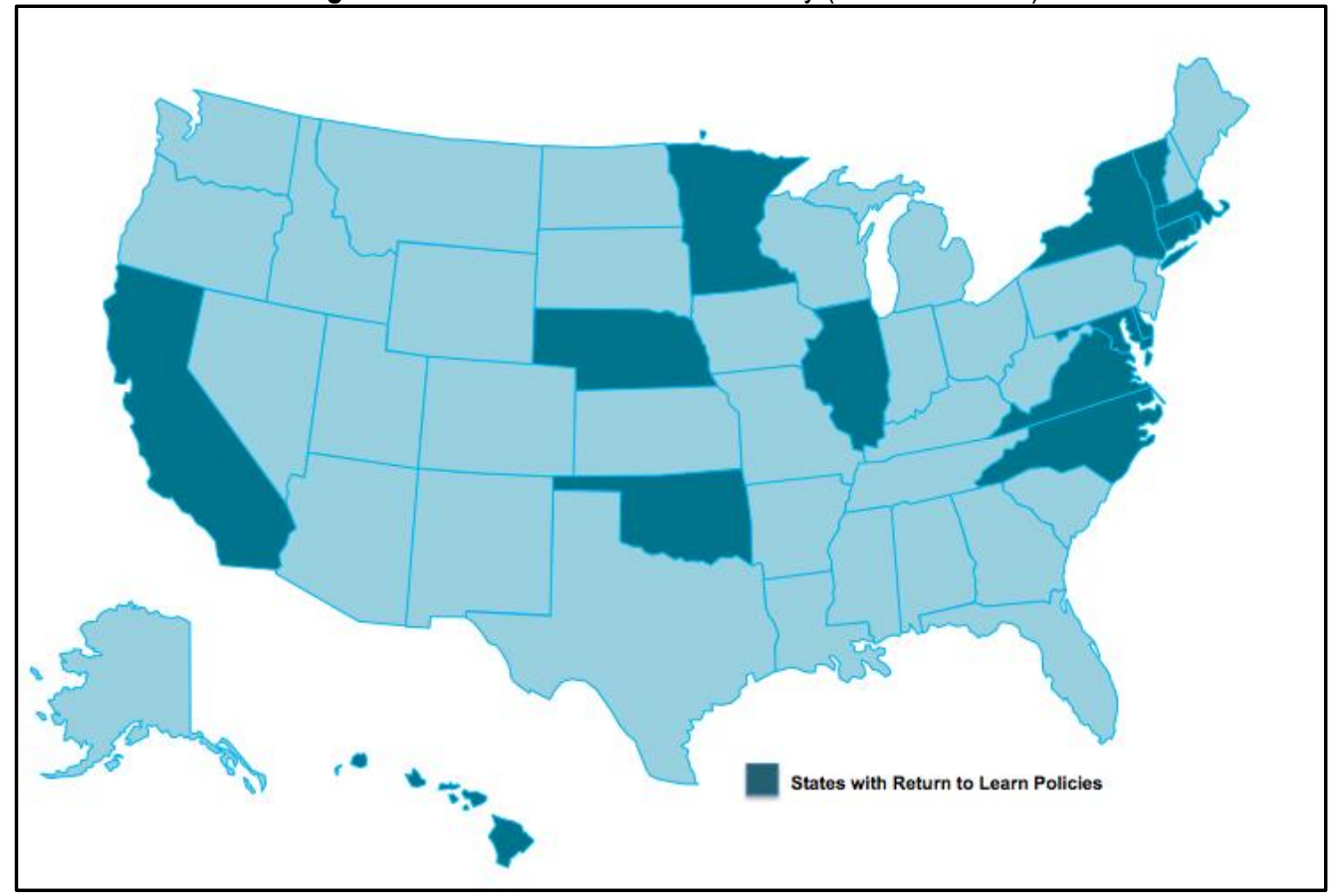

\section{DISCUSSION}

The purpose of this study was to examine sport concussion policy and provide healthcare practitioners with a comprehensive overview of current concussion related legislation, recognize limitations of such policies, and identify trends in policy revision. In order to do so, we identified four main components to concussion legislation: affected entities, 2) concussion awareness/education, 3) requirements for removal/return to play, and 4) requirements for return to the classroom (i.e. Return to Learn). Each of these legislative facets will be discussed below.

\section{Affected Entities}

Since 2009, every state in the nation and the District of Columbia passed legislation designed to protect student-athletes who suffer from concussions resulting from participation in sport. This legislation unanimously requires removal from play when a concussion is suspected and release for participation only after clearance by a designated healthcare provider. The final determination regarding an athlete's fitness for participation is based on the clinical judgment of the healthcare professional charged with the responsibility of clearing the athlete for participation. Failure to comply with the mandate may be considered negligence or failure to meet the standard of care causing injury. ${ }^{15}$ While protection from legal liability is a concern for stakeholders, the precedent for punitive processes against both individuals and school districts largely sides with the defendant. ${ }^{15}$ School officials need to ensure proper policies and procedures are in place as a professional responsibility and educational best practice. Furthermore, concussions are not exclusive to the athletic population. Each year approximately 2.5 million people suffer from traumatic brain injury. ${ }^{16}$ The majority of those injuries are attributed to falls, being struck in the head by an object, motor vehicle accidents or assault. Every child is susceptible to sustaining a concussion. However, in many states, every child is not afforded the protection provided by its state's concussion policy. With current concussion legislation in the United States, only $27 \%$ ( $N=13$ ) apply to public, private, and youth sports organizations.

\section{Concussion Awareness/Education}

Due to the lack of immediate access to healthcare professionals at sports practices and competitions, a widespread awareness of the signs and symptoms of a concussion among stakeholders in youth sports is needed. All current legislation requires some form of concussion education and initial reports suggest concussion legislation is raising the awareness of concussive symptoms. ${ }^{17}$ However, the laws vary greatly as to who is required to receive the training, if retraining is required, and if so, how often. ${ }^{18}$ Most states require an informed consent document signed prior to participation in sports. Of the states that require student-athlete education, the majority of policies suggest the education is in the form of informed consent only. Informed consent documents are not legally binding in cases involving minor. ${ }^{19}$ However, this practice ensures receipt of information and may improve compliance with reporting symptoms. ${ }^{20}$ The majority of state laws also mandate concussion training for coaches. This requirement is commonsense as coaches are present at each athletic event. Some policies specifically recommend either the Heads Up program 
by the Center for Disease Control, ${ }^{21}$ programming by the National Federation of State High School Associations, both, or an equivalent program. However, there are lingering questions regarding the method of delivery (i.e. live event, online module, written), who is charged with the delivery of the programming and how individuals completing the education are tracked. None of the policies include provisions for funding of the development, implementation, or distribution of educational programs. In all states, legal precedent specifies failure to train coaches on indicators of a concussion, maintain proper procedures to treat head injuries, and to instruct student athletes on the causes, symptoms and dangers of traumatic brain injuries may constitute as negligence by act of commission on part of the school district. ${ }^{15}$ There is conflicting evidence regarding the efficacy of concussion education. The literature ${ }^{22}$ suggests youth sport coaches can appropriately prevent, recognize and respond to concussions after reviewing the CDC's Heads Up information, thus, on one level, concussion education appears valuable. However, another study ${ }^{23}$ questions the efficacy of education programs and the quality of the education materials.

\section{Requirements for Removal/Return to play}

All 50 states plus the District of Columbia have legislation that requires a student-athlete to be removed from participation is a concussion is suspected and cannot return to participation until cleared by a healthcare professional. Maryland and Oklahoma are the only states to include ramifications for failure to comply with the law. In Maryland, a coach who allows a student-athlete to participate after a suspected concussion may be suspended. In Oklahoma, the offender (i.e. coaches, game officials, or administrators) must complete additional training for a first offense and can be suspended for future offenses. However, medical professionals are not readily available at all practices and competitions. Furthermore, if the evidence ${ }^{24}$ regarding the pressure coaches' place on medical professionals to prematurely return college athletes to play after a concussion is any indication, a conflict of interest may prevent the coach from adequately identifying an athlete with a suspected concussion. Therefore, it may be appropriate to also require education and/or mandates for unbiased stakeholders such as a referees or game officials to make the decision to remove a student-athlete from participation. Currently, only $22 \%(\mathrm{~N}=11)$ of laws include education for game officials.

\section{Return to Learn}

While state laws were originally passed to protect student-athletes from returning to sport participation while suffering from a head injury, we now know returning to the classroom while suffering from acute symptoms of a concussion is also problematic. ${ }^{25}$ Failure to respond appropriately to the disablements of a student suffering from concussive symptoms, most notably prolonged cases, may violate the Americans with Disabilities Education Act as well as Section 504 of the Rehabilitation Act. ${ }^{15,26}$ In order to better address the responsibilities of the school districts; the centerpiece in the revision of concussion legislation frequently involves the student's return to the classroom. Return to learn policies vary from requiring education regarding the effects of concussions on a student's academic performance to action plans that include a step-by-step protocol for re-entering the academic environment. The majority of concussion legislation seeks to address return to athletic participation while a limited number also include recommendations for reentering the academic environment. Protocols for return to the academic setting need to be established similar to those in place for return to play for both the medical safety of the student as well as for educational best practices. Similar to return to play strategies, return to learn protocols should be based upon the patient's symptoms and allows for a stepwise progression from complete cognitive rest to full return to school without academic adjustments. ${ }^{26,27}$ Common recommended academic accommodations focus mostly on cognitive rest strategies (i.e. postponing assignments, rest breaks, variation of attendance) as well as strategies to reduce physical symptoms (i.e. preferential seating, providing a note taker, or memory strategies). ${ }^{26-28}$ If an expansion of policy occurs, the number of individuals protected by the law increases but so does the number of stakeholders charged with implementing these policies. Teachers, nurses, counselors and other school administrators will need training in the recognition, standard treatment, and management of concussions as well as how the injury can affect the student's performance in the classroom. Conversely, healthcare professionals may need a better understanding of academic policy and educational interventions. ${ }^{28}$ Similar to the education requirement, no state policy specifically allocates funding for the application of return to learn mandates or include ramifications for failure to comply with said policies and procedures.

\section{CONCLUSION}

Many states are revisiting their concussion legislation in light of the rapidly evolving body of evidence in concussion research. It is the duty of healthcare professionals to advocate, educate, and serve as change agents for the safety and protection of all people. The first step in advocating for change is to petition for the same rights for all children and adolescents regardless of current state legislation. One way to do so is to express concern to your government representatives (i.e. Senators and Congressman) about your current law and its limitations. In addition, institutions that provide services to children and adolescents (e.g. school districts, parks and recreation departments) should create policy and procedures (i.e. return to learn, return to play) above what is mandated by state legislation so that all children and adolescents are protected equally. Finally, healthcare professionals associated with non-affected entities (i.e. private and charter schools, recreation leagues, park districts) should advocate for concussion education initiatives and be involved in the development of policies and procedures for return to learn and play.

@ The Internet Journal of Allied Health Sciences and Practice, 2018 


\section{REFERENCES:}

1. Faul M, Xu L, Wald M, Coronado V. Traumatic brain injury in the United States: emergency department visits, hospitalizations, and death. Atlanta, GA: Centers for Disease Control and Prevention, National Center for Injury Prevention 2010. Accessed November 7, 2017.

2. Cassidy J, Carroll L, Peloso P, Borg J, von Holst H, et al. Incidence, risk factors and prevention of mild traumatic brain injury: results of the WHO collaborating centre task force on mild traumatic brain injury. J Rehabil Med. $2004 \mathrm{Feb}(43$ Suppl):28-60. PMID 15083870

3. Patel DR, Parachuri V, Shettigar A. Evolution and management of sport-related concussions in adolescent athletes. . Transl Pediatr. 2017 July;6(3):121-8. PMID 28795001

4. Alder RH. Youth sports and concussions: preventing preventable brain injuries. Phys Med Rehabil Clin N Am. 2011;22:721-8. PMID 22050945

5. Potteiger A, Linzmeier K. Youth sports concussion safety act: addressing the care of youth with concussions in Illinois. Illinois Pediatrician. (Winter 2015-2016):7-10.

6. Halstead ME, Walter KD. Sport-related concussion in children and adolscents. Pediatrics. 2010;126(3):597-615. PMID 20805152

7. Broglio SP, Cantu RC, Gioia GA, Guskiewicz KM, Kutcher J, et al. National Athletic Trainers' Association position statement: management of sport concussion. J Athl Train. 2014;49(2):245-65. PMID 24601910

8. Alvarez B. A public health issue: getting athleti ctrainers into every high school. 2014. Available at: http://neatoday.org/2014/06/04/a-public-health-issue-getting-athletic-trainers-into-every-high-school/. Accessed November 7, 2017.

9. Hsieh HF, Shannon SE. Three approaches to qualitative content analysis. Qual Health Res. 2005;15(9):1277-1288. PMID 16204405

10. Manning PK, Cullum-Swan B. Handbook of Qualitative Research. Thousand Oaks, CA: Sage; 1994.

11. New Mexico (State). Legislature. SB0038. An Act Relating to Youth Athletics Safety; Requiring Brain Injury Training for Student and Other Youth Athletes. Available at: https://www.nmlegis.gov/Sessions/17\%20Regular/final/SB0038.pdf. Accessed: November 7, 2017.

12. Erickson MA, Martin M. Contributors to initial success on the National Athletic Trainers' Association Board of Certification examination as perceived by candidate sponsors: a delphi study J Athl Train. 2000;35(2):134-8. PMID 1323408

13. Bruce SL. Crawford E, Wilkerson GB, Rausch D, Dale RB, etal. Prediction modeling for academic success in professional master's athletic training programs. Athl Train Educ J. 2016; 11(4):194-207.

14. Buckner MM, Dietrich MS, Merriman C, Keeley JP. Identifying at-risk nursing students using a midcurricular examination. Comput Inform Nurs. 2013;31(5):229-34. PMID 23542307

15. Zirkel P. Court decisions specific to public school responses to student concussions. Phys Disabil. 2016;35(1):1-16.

16. Injury Prevention \& Control: Traumatic Brain Injury \& Concussion. TBI: Get the Facts. Available at: http://www.cdc.gov/traumaticbraininjury/get_the_facts.html, Accessed November 7, 2017.

17. Cuff S, Coxe K, Young J, Hongmei L, Yang J. Characteristics of Pediatric Patients Seen in Concussion Clinics Before and After Concussion Legislation. Paper presented at: American Medical Society for Sports Medicine 2016; Dallas, TX.

18. Harvey HH. Reducing traumatic brain injuries in youth sports: youth sports traumatic brain injury state laws, January 2009-December 2012. Am J Public Health. 2013;103(7):1249-1254.PMCID: PMC3682608

19. Raab E. The parameters of informed consent. Trans Am Ophthalmol Soc. 2004;102:225-32.

20. Bauch C, Kroshus E, Bourlas A, Perry K. Concussion and sports. J Law Med Ethics. 2014;42(3):297-313. PMID 25264088

21. Heads Up in 10 Years: The Anniversary Viewbook of CDC's Heads Up Atlanta, GA: Centers for Disease Control and Prevention; 2013. Available at: https://www.cdc.gov/headsup/pdfs/headsup_10yrviewbook-a.pdf. Accessed November 7, 2017.

22. Covassin T, Elbin RJ, Sarmiento K. Educating coaches about concussion in sports: evaluation of the CDC's "Heads Up: concussion in yourth sports" initiative. J Sch Health. 2012;82(5):233-8. PMID 22494094

23. Kroshus E, Daneshvar DH, Baugh CM, Nowinski CJ, Cantu RC. NCAA concussion education in ice hockey: an ineffective mandate. Br J Sports Med. 2014;48(2):135-40. PMID 23956336

24. Kroshus E, Baugh CM, Daneshvar DH, Stamm JM, Laursen RM, Austin SB. Pressure on sports medicine clinicians to prematurely return college athletes to play after concussion. J Athl Train. 2015;50(9):944-51. PMID 26207440

25. Carson JD, Lawrence DW, Kraft SA, Garel A, Snow CL, et al. Premature return to play and return to learn after a sportrelated concussion: a physician's chart review. Can Fam Physician. 2014;60(6):312-5. PMID 24925965

26. Halstead ME, McAvoy K, Devore CD, Carl R, Lee M, et al. Returning to learning following a concussion. Pediatrics. 2013;132(5):948-57. PMID 24163302

(C) The Internet Journal of Allied Health Sciences and Practice, 2018 
27. Master CL, Gioia GA, Leddy JJ, Grady MF. Importance of "return-to-learn" in pediatric and adolescent concussion. Pediatr Ann. 2012;41(9):1-6. PMID 22953975

28. Kasamatsu T, Cleary M, Bennett J, Howard K, McLeod TV. Examining academic support after concussion for the adolescent student-athlete: perspectives of the athletic trainer. J Athl Train. 2016;51(2):153-61. PMID 26942658 